\title{
The Impact of Pollen Donor on Flavor in Cocoa
}

\author{
Darin A. Sukha ${ }^{1}$ and Pathmanathan Umaharan \\ The Cocoa Research Centre, The University of the West Indies, St. Augustine, Trinidad and Tobago, \\ West Indies \\ David R. Butler \\ Street D, No 71, Jardim Atlântico, Ilhéus Bahia, Brazil
}

AdDitional INDEX words. mating design, pollination, flavor assessment, terroir effect

\begin{abstract}
The flavor attributes of cacao (Theobroma cacao) is becoming an important consideration in trade specifically for fine or flavor cocoa. In this market segment, flavor along with other physical attributes, not only contributes to the quality of a cocoa lot but also the price premium obtained. Past studies have shown evidence of pollen parent effects on yield, bean size, and pod characteristics, but its effect on flavor attributes is not clearly understood. An incomplete diallel mating design involving five cacao cultivars [West African Amelonado (WAA), Imperial College Selection (ICS) 1, Iquitos Mixed Calabacillo (IMC) 67, and two Trinidad Selected Hybrids (TSH) coded as CCL 200 and CCL 201] with widely differing flavor attributes were used to investigate the magnitude of female and male parent effects on key intrinsic flavor attributes. The seeds derived from pods arising from these pollinations were fermented, dried, and made into cocoa liquor according to standardized methods. Flavor evaluations were carried out by a trained sensory panel for nine flavor attributes with five repetitions and hidden flavor reference controls. The study was conducted over two cocoa crop years. The results failed to detect dominant xenia effects for important ancillary flavor attributes (i.e., cocoa flavor, acidity, fruitiness, and floral flavors), but showed significant female parent effects for cocoa and floral flavors. Small but inconsistent male parent effects were seen for astringency. Lack of xenia effect for the major flavor attributes implies that the flavor quality of cocoa beans is determined principally by the genotype of the female parent.
\end{abstract}

Cacao belongs to the family Malvaceae (Bayer et al., 1999) and originated as an under-story tree species in the tropical rainforests of the upper Amazonian region of South America (Butler and Umaharan, 2004; Mossu, 1992). The genus Theobroma contains some 22 species, and cacao is the only species that is cultivated on a large scale (Wood and Lass, 1985). Its current distribution extends across a belt $20^{\circ} \mathrm{N}$ and $15^{\circ} \mathrm{S}$ latitude. This tropical equatorial zone is characterized by heavy, welldistributed rainfall (1500 to $2000 \mathrm{~mm}$ ) with a distinct dry season, consistent high humidity and uniformly high temperatures throughout the year $\left(26\right.$ to $36^{\circ} \mathrm{C}$ ) (Mossu, 1992; Wood and Lass, 1985).

Traditionally, three different morpho-geographical groups (Criollo, Forastero, and Trinitario) were recognized within cacao, based on genetic origin, pod morphology, and size, as well as, color and flavor of beans (Engels, 1981; Laurent et al., 1994; Toxopeus, 1985). Motamayor et al. (2008) in a study of cacao germplasm from Central America and South America delineated 10 distinct genetic clusters using microsatellite markers. The results support the palaeoarches hypothesis of species diversification.

Cacao possesses an unusual incompatibility mechanism, first discovered by Pound (1932), which exhibits features of both sporophytic and gametophytic systems. Many studies have investigated this incompatibility system (Cope, 1939; Posnette, 1944, 1945; Voelcker, 1936) in cacao and its effect on planting systems and yield (Lockwood, 1977; Warren et al., 1995). Over the years, extensive work has been done on pollination biology of cacao (Dias and Kageyama, 1995; Dos Santos Dias et al., 2003; Lanaud, 1987, 1988; Yong Tan, 1990; Young, 1986,

Received for publication 12 May 2016. Accepted for publication 28 Nov. 2016. Special thanks are extended to Manickchand Estates Ltd. (Trinidad) and all sensory panelists for their assistance and Bruce Lauckner for statistical advice. ${ }^{1}$ Corresponding author. E-mail: darin.sukha@sta.uwi.edu.
2007; Young et al., 1987). Past studies have highlighted the many differences in fruit set, bean size, shape, color, and quality of the beans both within and between, particular cacao cultivars under natural and artificial pollination (Enríquez and Soria, 1968; Falque et al., 1995, 1996; Glendinning, 1963; Iwaro et al., 2003; Lachenaud, 1994, 1995).

A number of studies have described the specific effect of pollen parent on yield and some pod characteristics (Iwaro et al., 2003; Jacob and Toxopeus, 1969; Lockwood and Edwards, 1980). Although, Smulders et al. (2008) were able to differentiate the pollen donor contribution to particular pods from a known location using 15 microsatellite markers and were able to trace it to the chocolate made from these pods, they acknowledged that a link to flavor and pollen donor was needed but was outside the scope of their study. The only previous works attempting to link flavor to pollen donor effects in cocoa were that of Clapperton et al. (1994a, 1994b) and Lockwood and Eskes (1996). These preliminary studies reported lack of pollen donor effect on astringency involving cacao cultivars with markedly different levels of astringency. Lockwood and Eskes (1996) expressed surprise at the lack of xenia effect on flavor since xenia effects have been reported on cotyledon color. They concluded that more work needed to be done in this specific area to arrive at a clear answer, but also recognized that experiments to investigate this phenomenon posed "formidable technical difficulties."

The objective of the present study was therefore to investigate whether xenia effects exist for the various flavor attributes of cocoa over a range of crosses as part of a broader investigation examining factors possibly contributing to terroir in cocoa (Guittard, 2005; Nesto, 2010; Sukha et al., 2014).

\section{Materials and Methods}

Five cacao cultivars were chosen for this study (WAA, ICS 1, IMC 67, and TSH coded as CCL 200 and CCL 201) based on 
1) the availability of sufficient numbers of verified true-to-type trees (determined by morphological characterization and simple sequence repeat molecular marker analysis) and 2) their widely differing flavor attributes (Sukha et al., 2008). Each of the five parents was selfed where possible and mated with the other four parents in all possible combinations analogous to a $5 \times 5$ diallel mating design. Selfing was possible only with WAA and ICS 1 as the other cultivars were self-incompatible. The study was conducted over two cocoa crop years, as two trials. Selected crosses were done over both crop years to validate the repeatability of results (Table 1).

Trees selected for this study were pruned and fertilized 3 months before hand pollination to increase flowering and tree yield. These trees were also sprayed with a broad-spectrum pyrethroid insecticide and copper fungicide 1 week before hand pollination to remove ants (family Formicidae) and other crawling insects that could cause unwanted open pollinations and to eliminate any moss covering flower cushions.

Flower buds on trees selected as pollen donors and pollen recipients that would open within $24 \mathrm{~h}$ were identified by their rounded shape and marked lines separating the sepals. These flowers were covered with pollination hoods and secured to the tree with 25-mm-long stainless steel pins. The pollination hoods were made from fine mosquito netting arranged in a tent-like fashion (about $50 \mathrm{~mm}$ high). A layer of foam (about $6.5 \mathrm{~mm}$ thickness) was stuck around the base of the pollination hood, to conform to the irregular shape of the tree, forming a flexible but tight seal around the flower cushion, when attached with the stainless steel pins.

Hand pollinations were done between 0700 and $1200 \mathrm{HR}$ daily using the method described by Doodnath (1996). Pollinated flowers were monitored daily and a successful pollination was considered to have occurred when after $3 \mathrm{~d}$ the flower was in a "swollen ovary" state. This was the first visible sign that the ovules had been fertilized. Flowers usually abscised and fell off the tree within 24 to $48 \mathrm{~h}$ with unsuccessful pollinations.

The trees in this study were kept in an optimal physiological state by irrigation and application of a foliar fertilizer $(7 \mathrm{~N}-$ 9.6P-5.8K) to minimize the incidence of cherelle wilt. After 50 to $70 \mathrm{~d}$ when the susceptible period for cherelle wilt had passed, the immature pods were covered, where possible, with wire cages to prevent attacks by neotropical red squirrels (Sciurus

Table 1 . The five cacao cultivars selected for the study arranged in a $5 \times$ 5 diallel mating design for pollinations.

\begin{tabular}{clccccc}
\hline & & \multicolumn{5}{c}{ Male parent $^{\mathrm{z}}$} \\
\cline { 3 - 7 } & & WAA & ICS 1 & IMC 67 & CCL 200 & CCL 201 \\
\hline Female & WAA & $1,2^{\mathrm{y}}$ & 1,2 & 1,2 & 1,2 & 1,2 \\
parent $^{\mathrm{z}}$ & ICS 1 & 1,2 & 1,2 & 1,2 & 1 & 1,2 \\
& IMC 67 & 1 & 1 & SI & 1 & 1 \\
& CCL 200 & 1,2 & 1 & 1 & SI & 1 \\
& CCL 201 & 1,2 & 1,2 & 1,2 & 1,2 & SI \\
\hline
\end{tabular}

${ }^{\mathrm{z} C u l t i v a r s}$ West African Amelonado (WAA), Imperial College Selection (ICS) 1, Iquitos Mixed Calabacillo (IMC) 67, and two Trinidad Selected Hybrids (TSH) coded as CCL 200 and CCL 201 were selfed where possible and mated with the other four parents in all possible combinations analogous to a $5 \times 5$ diallel mating design carried out over two crop years, trials 1 and 2, to study the effect of male and female parent effects of flavor attributes in cocoa.

${ }^{\mathrm{y}} 1,2=$ crosses done in both trials 1 and $2,1=$ crosses done in trial 1 alone, $\mathrm{SI}=$ self-incompatible types. granatensis) and orange-winged parrots (Amazona amazonica). The cages were large enough for the pod to develop without restriction and were used when the morphology of the tree, in relation to the position of the immature pod allowed it to be put in place. Immature pods were checked weekly and sprayed with copper fungicide in two heavy applications $\left(30 \mathrm{~g} \cdot \mathrm{m}^{-2}\right)$ mixed with a sticker solution $\left(0.5 \mathrm{~mL} \cdot \mathrm{m}^{-2}\right)$ during the 6-month growing period to protect against black pod disease (Phytophthora $\mathrm{sp}$.)

Fully mature disease-free pods from successful pollinations were harvested and both primary (fermentation and drying) and secondary (bean roasting and liquor preparation) processing were conducted using the methods described in Sukha et al. (2008). Sensory panel training as well as flavor evaluations were also carried out according to the methods described in Sukha et al. (2008).

As a summary, panel training and sample evaluations were conducted in a quiet, air-conditioned room. A pool of eight sensory panelists were screened to assess their availability and general attitude toward flavor evaluations via a written questionnaire and then trained through a series of tests that increased in complexity. These tests included identification of basic tastes using aqueous solutions at normal and threshold level concentrations followed by paired comparison, ranking tests, and flavor profiling over eight key flavor attributes associated with cocoa liquor; i.e., cocoa, acid, astringent, bitter, fruity, floral, nutty, and raw/beany/green flavors. Identifiable off-flavors such as smoky, hammy, mouldy, and unfermented were also considered. Any other ancillary flavors or defects present in the samples were considered in a section for "other" flavors making nine flavor attributes assessed in total (Sukha et al., 2008).

A panel of the same six trained individuals selected from the pool of eight persons assessed the cocoa liquor samples from the two trials over the two crop years using a factorial statistical design that incorporated hidden reference liquors in the sensory design to control panelist consistency between the five repetitions of evaluations. Liquors were coded with three-digit numbers and randomized to minimize carry-over effects. No two panelists received liquors in the same order for any given evaluation session and a maximum of six liquors were tasted in any one session to prevent panelist fatigue (Sukha et al., 2008).

The coded samples were melted at $45^{\circ} \mathrm{C}$ and presented to the panelists in 20-mL glasses placed in a hollowed-out aluminum block, which had been preheated to $55^{\circ} \mathrm{C}$ to keep the samples warm during tasting. For evaluation, panelists were asked to place about $1 \mathrm{~mL}$ of cocoa liquor on a teaspoon in their mouth and keep it there for $20 \mathrm{~s}$. During this time, the different attributes making up the flavor profile became apparent at three contiguous time intervals; i.e., initial front flavor notes, middle flavor notes, and residual end flavor notes (Sukha et al., 2008).

Sensory profiles were recorded for the flavor attributes using $10-\mathrm{cm}$ line scales with a possible range of scores from 0 to 10 where the higher numbers denoted stronger flavor intensities. Panelists expectorated the sample and then cleansed their palate with a biscuit cracker and water between each sample (Sukha et al., 2008).

Data on individual flavor attribute scores from the two trials were entered into Microsoft Excel (Microsoft, Redmond, WA) for a pooled analysis. The sensory data were subjected to analysis using analysis of variance (ANOVA), paired $t$ tests, Tukey-Kramer test, and linear regression analysis. Female 
parent $\times$ pollen donor interactions were determined from ANOVA.

It was not possible to use the entire dataset at the same time for ANOVA, due to the presence of self-incompatible crosses in the diallel mating design and since the study was conducted as two trials over two crop years. To address this, a number of smaller diallels on combined trial 1 and trial 2 data were created from the crosses in the main $5 \times 5$ diallel design presented in Table 2.

General linear model (GLM) ANOVA using Minitab (release 14; Minitab, State College, PA) was carried out on data from each smaller diallel for trials 1 and 2 to determine the significance of female parent, pollen donor, and female parent $\times$ pollen donor interaction effects over the five repetitions of flavor evaluations per sample. The F test values from the GLM ANOVA were used to gauge the relative magnitude of the effects.

Paired $t$ tests were done to give better resolution to the ANOVA results by focusing on the difference between paired sets of reciprocal crosses and presenting the probability that the actual mean difference was consistent with zero. Comparisons of reciprocal crosses allow examination of significant effects on flavor with a specific combination of crosses and involved the same pair of accessions where each

Table 2. Smaller diallel designs created with the five cacao cultivars selected for the study.

\begin{tabular}{|c|c|c|}
\hline Diallels ${ }^{z}$ & Female parents & Male parents \\
\hline \multirow[t]{5}{*}{ Diallel $1(2 \times 5)$} & WAA & WAA \\
\hline & ICS 1 & ICS 1 \\
\hline & & IMC 67 \\
\hline & & CCL 200 \\
\hline & & CCL 201 \\
\hline \multirow[t]{5}{*}{ Diallel $2(5 \times 2)$} & WAA & WAA \\
\hline & ICS 1 & ICS 1 \\
\hline & IMC 67 & \\
\hline & CCL 200 & \\
\hline & CCL 201 & \\
\hline \multirow[t]{3}{*}{ Diallel $3(2 \times 3)$} & CCL 200 & WAA \\
\hline & CCL 201 & ICS 1 \\
\hline & & IMC 67 \\
\hline \multirow[t]{3}{*}{ Diallel $4(3 \times 2)$} & WAA & CCL 200 \\
\hline & ICS 1 & CCL 201 \\
\hline & IMC 67 & \\
\hline \multirow[t]{4}{*}{ Diallel $5(4 \times 3)$} & WAA & WAA \\
\hline & ICS 1 & ICS 1 \\
\hline & IMC 67 & CCL 201 \\
\hline & CCL 200 & \\
\hline \multirow[t]{4}{*}{ Diallel $6(3 \times 4)$} & WAA & WAA \\
\hline & ICS 1 & ICS 1 \\
\hline & CCL 201 & IMC 67 \\
\hline & & CCL 200 \\
\hline
\end{tabular}

$\overline{{ }^{\mathrm{z}} \text { Smaller diallel mating designs were created to facilitate analysis of }}$ variance due to the presence of self-incompatible crosses in the mating design and because the study was conducted as two trials over two crop years.

${ }^{y}$ Cultivars West African Amelonado (WAA), Imperial College Selection (ICS) 1, Iquitos Mixed Calabacillo (IMC) 67, and two Trinidad Selected Hybrids (TSH) coded as CCL 200 and CCL 201) were used in smaller diallel mating designs created from the crosses in the main $5 \times 5$ diallel design presented in Table 1 . accession has the opportunity to be the female parent and pollen donor in turn.

\section{Results}

The ANOVA results from the pooled trial 1 and trial 2 data (Table 3) showed a general trend indicating that the female parent effects were significant $(P \leq 0.001$ to 0.05$)$ in majority of the diallels for cocoa, acid, floral, nutty, raw/beany/green, and other flavor attributes, whereas the female parent effects for astringency and fruity flavors were significant only in one diallel, each. In contrast, the male parent effects were not significant for all flavor attributes in vast majority of the diallels, except nutty and other which showed significant male parent effects in some diallel designs. Significant interaction effects ( $P \leq 0.001$ to 0.05 ) were evident for nutty and other flavor attributes in several diallels. Even when the interaction was significant in two diallels for cocoa flavor and one diallel for floral, the magnitude of the $F$ value was smaller than the female parent effects. Bitterness was the only flavor attribute that did not show significance $(P \leq 0.001$ to 0.05 ) for male parent, female parent, or male parent $\times$ female parent interaction effects.

Paired $t$ test between reciprocal crosses revealed that the greatest significant $(P<0.001)$ effect was observed for floral flavor. This effect was strongest (greatest difference in average scores) when CCL 200 was the female parent in the cross. The largest difference in floral flavor occurred when crosses ICS $1 \times$ CCL 200 and CCL $200 \times$ ICS 1 were compared with each other. Their average scores for floral were 0.55 and 5.78, respectively, on the 10-point attribute scale. Other reciprocal crosses with big differences in floral flavor occurred with CCL $201 \times$ CCL 200 and CCL $200 \times$ CCL 201 as well as WAA $\times$ CCL 200 and CCL $200 \times$ WAA (0.98 and 6.15; 0.35 and 5.14, respectively).

Significant $(P \leq 0.001$ to 0.05$)$ reciprocal effects, albeit with smaller differences between reciprocals, were observed for cocoa flavor, astringency and other flavors, whereas no significant reciprocal effects $(P>0.05)$ were observed for acid and fruity flavors. Although reciprocal crosses do not specifically identify female parent or pollen donor effects, they do allow examination of significant effects on flavor with a specific combination of crosses. These effects occurred in reciprocal crosses involving CCL 200, CCL 201 (cocoa flavor and astringency) and WAA, CCL 200 (other flavors). Similarly, significant $(P \leq 0.01)$ reciprocal effects were observed for nutty flavor when WAA, ICS 1; WAA, CCL 200; and CCL 200, CCL 201 were the parents in reciprocal crosses.

Linear regression analyses from pooled trial 1 and trial 2 sensory data were carried out to determine whether the average score for each cultivar overall crosses as male or female parent was related to the score of the actual cross. The independent variable in the linear regression was obtained from the average scores for all possible combinations of crosses, repetitions, and trials in the overall diallel mating design (Table 1) for each female parent in turn. Averages for similar combinations were also calculated for each pollen donor in turn. The dependent variable was derived from the average score for a particular flavor attribute, for each individual cross.

A summary of significance of linear relationships between $(P \leq 0.001$ to 0.05$)$ female parent and progeny and pollen donor and progeny are presented in Table 4 using the values of slope and the significance of these values, as well as, magnitude of 


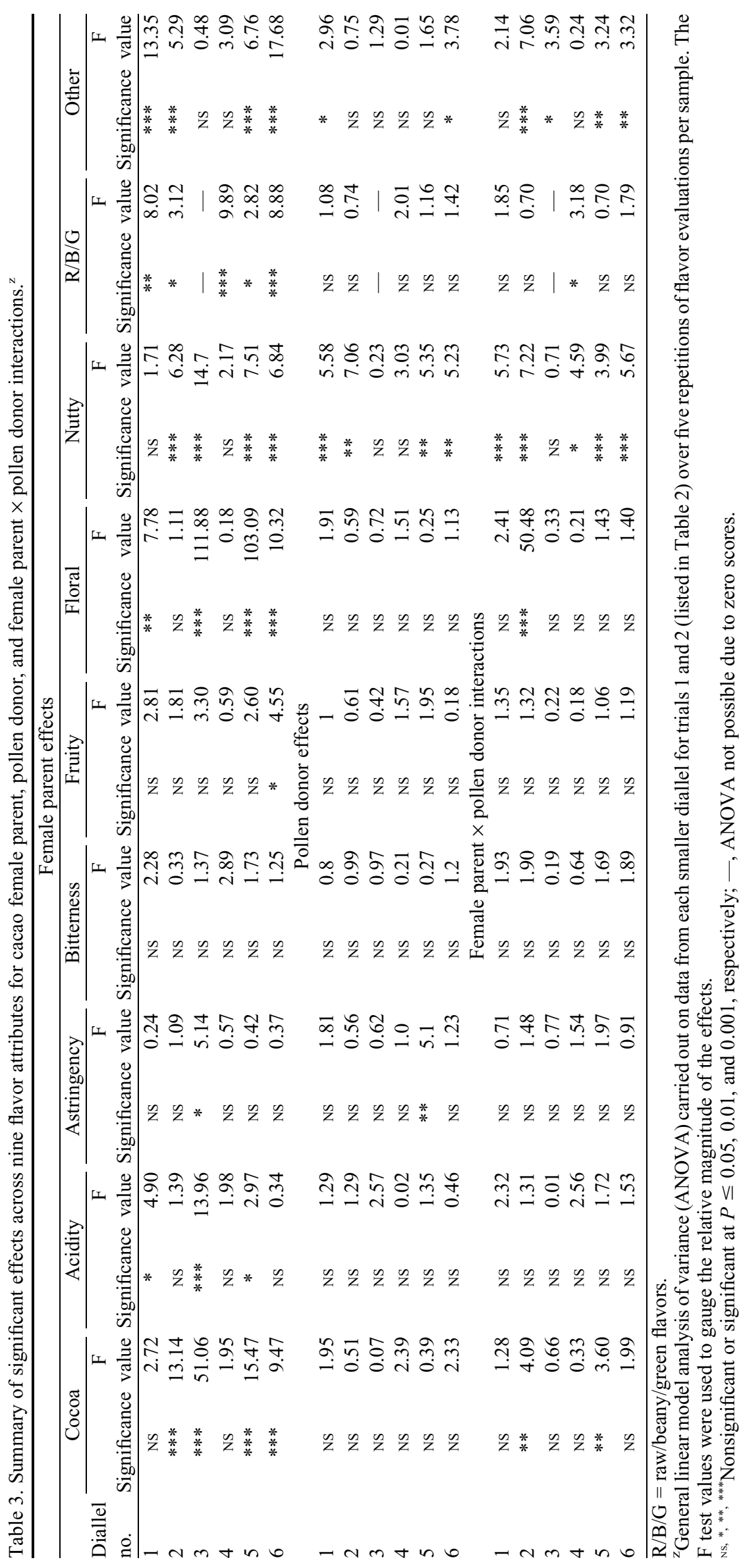


these effects (given by the $t$ statistic values) from linear regression analyses. There were significant $(P \leq 0.001$ to 0.05) female parent effects for all flavor attributes except astringency, indicated by slopes significantly $(P \leq 0.001$ to 0.05) larger than zero. The slopes were particularly large for floral and cocoa flavors ( 0.72 and 0.96 , respectively) and significantly different from zero indicating a strong dependency of the female parent for floral and cocoa flavors (Table 4). The coefficient of determination for the regressions were 0.72 and 0.97 for cocoa and floral flavors, respectively. In contrast the male parent effect on bean quality was largely not significant except for astringency which was significant at $P<0.05$.

\section{Discussion}

Pollen donor effects have been studied in other crops, such as apple (Malus pumila) and sour cherry (Prunus cerasus), for other quality attributes such as firmness and acid content (Davarynejad et al., 1994) and fruit size and total soluble solids (Ansari and Davarynejad, 2008) but rarely on flavor.

The objective of this study was to examine the effect of pollen donor on the flavor attributes of selected cacao cultivars to determine if there was a xenia effect on flavor and the diallel mating design provided an effective framework to carry out controlled hand pollinations to investigate this premise.

The optimized organoleptic evaluation methods (Sukha et al., 2008) provided robust data that were able to provide statistically valid results. This highlights the effectiveness of

Table 4. Summary of the values of slope from linear regression analyses performed on pooled trial 1 and trial 2 sensory data across nine flavor attributes for cacao female parent and pollen donor effects. $^{\mathrm{z}}$

\begin{tabular}{lccccc}
\hline \multicolumn{7}{c}{ Female parent effects } \\
\hline Flavor attribute & Slope & SE & $t$ Statistic & $P$ value & $\begin{array}{c}\text { Significance } \\
\text { level }\end{array}$ \\
\hline Cocoa & 0.72 & 0.10 & 7.23 & 0.000 & $* * *$ \\
Acid & 0.55 & 0.11 & 5.18 & 0.000 & $* * *$ \\
Astringency & 0.11 & 0.07 & 1.59 & 0.128 & NS \\
Bitterness & 0.36 & 0.10 & 3.41 & 0.003 & $* *$ \\
Fruity & 0.62 & 0.11 & 5.73 & 0.000 & $* * *$ \\
Floral & 0.96 & 0.03 & 27.85 & 0.000 & $* * *$ \\
Nutty & 0.39 & 0.10 & 3.81 & 0.001 & $* * *$ \\
Raw/beany/green & 0.44 & 0.09 & 4.63 & 0.000 & $* * *$ \\
Other & 0.62 & 0.11 & 5.67 & 0.000 & $* * *$ \\
& Pollen donor effects & & \\
Cocoa & 0.03 & 0.05 & 0.60 & 0.558 & NS \\
Acid & 0.03 & 0.03 & 0.72 & 0.477 & NS \\
Astringency & 0.22 & 0.08 & 2.66 & 0.015 & $*$ \\
Bitterness & 0.14 & 0.08 & 1.70 & 0.104 & NS \\
Fruity & 0.11 & 0.08 & 1.42 & 0.171 & NS \\
Floral & 0.02 & 0.03 & 0.60 & 0.553 & NS \\
Nutty & 0.10 & 0.07 & 1.47 & 0.156 & NS \\
Raw/beany/green & 0.06 & 0.05 & 1.19 & 0.249 & NS \\
Other & 0.12 & 0.09 & 1.33 & 0.197 & NS \\
\hline
\end{tabular}

${ }^{\mathrm{z}}$ Significance $(P \leq 0.001$ to 0.05$)$ of these values, as well as, magnitude of these effects (given by the $t$ statistic) determine whether the average flavor score for each cacao cultivar across nine flavor attributes was related to the score of the actual pollination cross.

Ns, ${ }^{*},{ }^{* *},{ }^{* * *}$ Nonsignificant or significant at $P \leq 0.05,0.01$, and 0.001 respectively. the sensory design in being able to provide data from which we are able to resolve significant effects from small differences in scores. The results showed that flavor of cocoa beans was determined largely by the genotype of the female parent and with a possible marginal effect of pollen donor on flavor, confined mainly to astringency, nutty, and other flavors. Due to the inconsistency of significance of male parent effects over crosses and the relatively small effects, one cannot preclude type II error. However, F test values and $t$ statistic values were presented where possible for each flavor attribute to gauge the relative magnitude of the male and female parent effects observed.

The possibility of the pollen donor contributing to bean flavor originates from the fact that the endosperm of the seed is determined by male and female gametes. However, this appears to be superseded by the strong influence of the seedcoat and mucilage (pulp), that is entirely maternally derived since the integument of the matured ovule develops into the seedcoat which shares the same diploid genotype of the mother tree (Fang et al., 2014). Fresh cocoa seeds are characterized by an astringent and bitter taste due to the high content of phenolics, especially anthocyanins (Jinap et al., 2005) and because they do not contain the necessary aroma precursors (Ziegleder and Biehl, 1988). Bitterness most probably displayed no significant effects as all the bean samples were fermented and this is attribute is more prevalent in unfermented and under-fermented samples.

Many authors including Andersson et al. (2006) have highlighted the kinetics of bean acidification during fermentation, on flavor development. The maternally derived seedcoat and pulp is degraded by yeasts, lactic, and acetic acid bacteria resulting in lactic and acetic acid formation as a result of exothermic reactions. The acids permeate though the differentially permeable seedcoat into the seed tissue and, together with the heat evolved during fermentation, cause seed death. The storage proteins and carbohydrates are subsequently degraded by seed enzymes yielding aroma precursors which are peptides, free amino acids, and reducing sugars (Afoakwa et al., 2008; Andersson et al., 2006; Kadow et al., 2013; Schwan and Wheals, 2004; Ziegleder and Biehl, 1988).

In addition to the endogenous formation of flavor and aroma precursors from fermentation and drying, there is also mounting evidence for the exogenous influence of the pulp directly on aroma and flavor development. Eskes et al. (2007, 2012) discuss the direct permeation of aroma components from the pulp into the seed tissue during fermentation that may be retained during the drying process.

The study therefore failed to detect xenia effects for most of the important flavor attributes, i.e., cocoa flavor, acidity, fruitiness, and floral flavor which agrees with the preliminary work of Clapperton et al. (1994a, 1994b) and Lockwood and Eskes (1996) suggesting a general lack of xenia effect on flavor in cacao.

Fruity flavor notes did not have a strong genotypic effect (either male or female parent effects). The results and other studies (Sukha et al., 2014) suggest that fruity flavor and other ancillary flavors may be affected by the local growing environment and postharvest processing contributing to a sense of place or terroir for flavor development in cocoa (Guittard, 2005; Nesto, 2010; Sukha et al., 2014). Terroir is concerned with the relationship between the characteristics of an agricultural product (quality, taste, style) and its geographic origin, which 
might influence these characteristics (van Leeuwen and Seguin, 2006). This concept has been demonstrated extensively in viticulture as the sensory attributes of wine have been related to the environmental conditions in which the grapes are grown but are challenging to study systematically because many factors are involved, including climate, soil, cultivar, microbial environment during fermentation, and human practices (Bokulich et al., 2016; van Leeuwen and Seguin, 2006).

On the other hand, a significant effect of the female parent was detected for floral flavor followed by cocoa flavor evident from the strong reciprocal differences seen. These point to the importance of the female parent in determining these attributes. Indeed, Kadow et al. (2013) highlighted quantitative and qualitative differences in the aromatic profile of fruit pulp from different cocoa cultivars and that aroma components present in the fruit pulp migrate into the cotyledon tissue during ripening in addition to those derived from fermentation.

The findings from this study therefore highlight a lack of xenia effect for the major flavor attributes implies that the flavor quality of cocoa beans is determined principally by the genotype of the female parent.

\section{Literature Cited}

Afoakwa, E.O., A. Paterson, M. Fowler, and A. Ryan. 2008. Flavor formation and character in cocoa and chocolate: A critical review. Crit. Rev. Food Sci. Nutr. 48:840-857.

Andersson, M., G. Koch, and R. Lieberi. 2006. Structure and function of the seed coat of Theobroma cacao L. and its possible impact on flavor precursor development during fermentation. J. Appl. Bot. Food Qual. 80:48-62.

Ansari, M. and G.H. Davarynejad. 2008. Marked improvement of Hungarian sour cherries by cross pollination II: Fruit quality. Asian J. Plant Sci. 7:771-774.

Bayer, C., M.F. Fay, A.Y. De Bruijn, V. Savolainen, C.M. Morton, K. Kubitzki, W.S. Alverson, and M.W. Chase. 1999. Support for an expanded family concept of Malvaceae within a recircumscribed order Malvales: A combined analysis of plastid $a t p \mathrm{~B}$ and $r c b \mathrm{~L}$ DNA sequences. Bot. J. Linnean Soc. 129:267-303.

Bokulich, N.A., T.S. Collins, C. Masarweh, G. Allen, H. Heymann, S.E. Ebeler, and D.A. Mills. 2016. Associations among wine grape microbiome, metabolome, and fermentation behavior suggest microbial contribution to regional wine characteristics. MBio 7: e00631-e16.

Butler, D.R. and P. Umaharan. 2004. Working with cocoa germplasm, p. 54-64. In: J. Flood and R. Murphy (eds.). Cocoa futures-A source book of some important issues confronting the cocoa industry. Commodities Press, Chinchiná, Colombia.

Clapperton, J.F., S.T.K. Yow, J. Chan, and D.H.K. Lim. 1994a. Effects of planting materials on flavor. Cocoa Growers Bul. 48.

Clapperton, J.F., S.T.K. Yow, D.H.K. Lim, and G. Lockwood. 1994b. Genetic variation in cocoa flavor. Proc. Intl. Cocoa Res. Conf. 11:749-758.

Cope, F.W. 1939. A note on the range of compatibility in cacao. Annu. Rpt. Cocoa Res. Unit 1938. Cocoa Res. Unit, Univ. West Indies, St. Augustine, Trinidad and Tobago, West Indies.

Davarynejad, G.H., J. Nyéki, J. Hámori Szabó, and Z. Lakner. 1994. Relationship between pollen-donors and quality of fruits of 12 apple cultivars. Acta Hort. 368:344-354.

Dias, L.A.S. and P.Y. Kageyama. 1995. Combining-ability for cacao (Theobroma cacao L.) yield components under southern Bahia conditions. Theor. Appl. Genet. 90:534-541.

Doodnath, R. 1996. A study of intergeneric hybridization between (Theobroma cacao L.) and Herrania species. MPhil Thesis, Univ. West Indies, St. Augustine, Trinidad and Tobago, West Indies.
Dos Santos Dias, L.A., J. Martina, C. Damião Cruz, E. Gonçalves de Barros, and T. Fernández Salomão. 2003. Genetic distance and its association with heterosis in cacao. Braz. Arch. Biol. Technol. 46:339-347.

Engels, J.M.M. 1981. Genetic resources of cacao: A catalogue of the Centro Agronómico Tropical de Investigación y Enseñanza collection. Turrialba, Costa Rica, Tech. Bul. 7.

Enríquez, G. and J. Soria. 1968. The variability of certain bean characteristics of cacao (Theobroma cacao L.). Euphytica 17:114120.

Eskes, A.B., D. Ahnert, L.C. Garcia, E. Seguine, S. Assemat, D. Guarda, and P.R. Garcia. 2012. Evidence on the effect of the cocoa pulp flavour environment during fermentation on the flavour profile of chocolates. 21 July 2016. < http://agritrop.cirad.fr/568108/1/ document_568108.pdf>.

Eskes, A.B., D. Guarda, L. Garcia, and P. Garcia. 2007. Is genetic variation for sensory traits of cocoa pulp related to fine flavor cocoa traits? INGENIC Nwsl. 11:22-28.

Falque, M., C. Lesdalons, and A.B. Eskes. 1996. Comparison of two cacao (Theobroma cacao L.) clones for the effect of pollination intensity on fruit set and seed content. Plant Reprod. 9:221-227.

Falque, M., A. Vincent, B.E. Vaissiere, and A.B. Eskes. 1995. Effect of pollination intensity on fruit and seed set in cacao (Theobroma cacao L.). Plant Reprod. 8:354-360.

Fang, W., L. Meinhardt, S. Mischke, C.M. Bellato, L. Motilal, and D. Zhang. 2014. Accurate determination of genetic identity for a single cacao bean, using molecular markers with a nanofluidic system, ensures cocoa authentication. J. Agr. Food Chem. 62:481-487.

Glendinning, D.R. 1963. The inheritance of bean size, pod size and number of beans per pods in cocoa (Theobroma cacao L.), with a note on bean shape. Euphytica 12:311-322.

Guittard, G.W. 2005. Origin cocoa: Vive la différence. The Manufacturing Confectioner 85:81-88.

Iwaro, A.D., F.L. Bekele, and D.R. Butler. 2003. Evaluation and utilization of cacao (Theobroma cacao L.) germplasm at the International Cocoa Genebank, Trinidad. Euphytica 130:207-221.

Jacob, V.J. and H. Toxopeus. 1969. The effect of pollinator parent on the pod value of hand pollinated pods of Theobroma cacaosssss L. Proc. Intl. Cocoa Res. Conf. 3:556-559.

Jinap, S., B. Jamilah, and S. Nazamid. 2005. Changes in polyphenol ability to produce astringency during roasting of cocoa liquor. J. Sci. Food Agr. 85:917-924.

Kadow, D., J. Bohlmann, W. Phillips, and R. Lieberei. 2013. Identification of main fine or flavour components in two genotypes of the cocoa tree (Theobroma cacao L.). J. Appl. Bot. Food Qual. 86:90-98.

Lachenaud, P. 1994. Variations in the number of beans per pod in (Theobroma cacao L.) in the Ivory Coast. I. The role of pollen. J. Hort. Sci. 69:1123-1129.

Lachenaud, P. 1995. Variations in the number of beans per pod in (Theobroma cacao L.) in the Ivory Coast. II. Pollen germination, fruit setting and ovule development. J. Hort. Sci. 70:1-6.

Lanaud, C. 1987. Double haploids of cocoa (Theobroma cacao L.) 2. Observations of monogenic and polygenic characters. Plant Breed. 99:196-202.

Lanaud, C. 1988. Origin of haploids and semigamy in Theobroma cacao L. Euphytica 38:221-228.

Laurent, V., A.M. Risterucci, and C. Lanaud. 1994. Genetic diversity in cocoa revealed by cDNA probes. Theor. Appl. Genet. 88:193-198.

Lockwood, G. 1977. Studies on the effects of cross-incompatibility on the cropping of cocoa in Ghana. J. Hort. Sci. 52:113-126.

Lockwood, G. and D.F. Edwards. 1980. Determination of pod and bean characters in progeny trials with cocoa. Trop. Agr. (Trinidad) 57: 289-300.

Lockwood, G. and A.B. Eskes. 1996. Relationship between cocoa variety and quality, p. 159-167. Proc. Cocoa Meetings-The various aspects of quality. Centre de coopération internationale 
en recherche agronomique pour le développement, Montpellier, France.

Mossu, G. 1992. Cocoa, p. 10-22. In: R. Coste (ed.). The tropical agriculturalist. MacMillan, London, UK.

Motamayor, J.C., P. Lachenaud, J.W. da Silva e Mota, R. Loor, D.N. Kuhn, J.S. Brown, and R.J. Schnell. 2008. Geographic and genetic population differentiation of the Amazonian chocolate tree (Theobroma cacao L). PLoS One 3(10):e3311.

Nesto, B. 2010. Discovering terroir in the world of chocolate. Gastronomica 10:131-135.

Posnette, A.F. 1944. Pollination of cacao in Trinidad. Trop. Agr. (Trinidad) 21:115-118.

Posnette, A.F. 1945. Incompatibility in Amazon cacao. Trop. Agr. (Trinidad) 22:184-187.

Pound, F.J. 1932. The principles of cocoa selection. Proc. Agr. Soc. Trinidad Tobago 32:122-127.

Schwan, R.F. and A.E. Wheals. 2004. The microbiology of cocoa fermentation and its role in chocolate quality. Crit. Rev. Food Sci. Nutr. 44:205-221.

Smulders, M.J.M., D. Esselink, F. Amores, G. Ramos, D.A. Sukha, D.R. Butler, B. Vosman, and E.N. van Loo. 2008. Identification of cocoa (Theobroma cacao L.) varieties and parentage analysis of their beans. 10 June 2016. <https://www.wageningenur.nl/en/Publication-details. htm?publicationId=publication-way-343238303739>.

Sukha, D.A., D.R. Butler, E.A. Comissiong, and P. Umaharan. 2014. The impact of processing location and growing environment on flavor in cocoa (Theobroma cacao L.) - Implications for terroir and certification-Processing location study. Acta Hort. 1047:255-262.
Sukha, D.A., D.R. Butler, P. Umaharan, and E. Boult. 2008. The use of an optimized assessment protocol to describe and quantify different flavor attributes of cocoa liquors made from Ghana and Trinitario beans. Eur. Food Res. Technol. 226:405-413.

Toxopeus, H. 1985. Botany, types and populations, p. 11-37. In: G.A.R. Wood and R.A. Lass (eds.). Cocoa. 4th ed. Longman, London, UK.

van Leeuwen, C. and G. Seguin. 2006. The concept of terroir in viticulture. J. Wine Res. 17:1-10.

Voelcker, O.J. 1936. Self-incompatibility in cacao. Annu. Rpt. Cocoa Res. Unit 1936. Cocoa Res. Unit, Univ. West Indies, St. Augustine, Trinidad and Tobago, West Indies.

Warren, J., S. Kalai, and S. Misir. 1995. An unnatural breeding system polymorphism in cacao (Theobroma cacao, Sterculiaceae) in Trinidad. Amer. J. Bot. 82:1126-1130.

Wood, G.A.R. and R.A. Lass (eds.). 1985. Cocoa. 4th ed. Longman, London, UK.

Yong Tan, G. 1990. Combining ability analysis of yield and its components in cacao. J. Amer. Soc. Hort. Sci. 115:509-512.

Young, A.M. 1986. Cocoa pollination. Cocoa Growers Bul. 37.

Young, A.M. 2007. The chocolate tree: A natural history of cacao. Univ. Press Florida, Gainesville, FL.

Young, A.M., E.H. Erickson, M.A. Strand, and B.J. Erickson. 1987. Pollination biology of Theobroma and Herrania (Sterculiaceae)-I. Floral biology. Insect Sci. Appl. 8:151-164.

Ziegleder, V.G. and B. Biehl. 1988. Analysis of cocoa flavor components and flavor precursors, p. 321-390. In: H.J. Likens and J.F. Jackson (eds.). Modern methods of plant analysis. SpringerVerlag, Berlin, Germany. 